\title{
Prevalence of family violence and mental health and their relation to peer victimization: A representative study of adolescent students in Southwestern Uganda
}

\author{
Joseph Ssenyonga $^{\mathrm{a}}$, Charles Magoba Muwonge ${ }^{\mathrm{b}}$, Tobias Hecker ${ }^{\mathrm{c}, \mathrm{d}}{ }_{*}$ \\ ${ }^{a}$ Department of Psychology, University of Konstanz, 78567 Konstanz, Germany \\ ${ }^{\mathrm{b}}$ Department of Educational Foundations and Psychology, Mbarara University of Science and Technology, P.O. Box 1410, Uganda \\ ${ }^{\mathrm{c}}$ vivo International, 78340 Konstanz, Germany \\ ${ }^{\mathrm{d}}$ Department of Psychology, University of Bielefeld, 33501 Bielefeld, Germany
}

Keywords:

Family violence

Mental health

Peer victimization

Adolescents

Students

\begin{abstract}
A B S T R A C T
Background: Despite global efforts to end violence against children in all settings, reports reveal that violence against children is still highly prevalent, especially in low-and middle- income countries. Violence in childhood is associated with a host of negative outcomes, and exposure in one setting can easily spill over to other contexts. For instance, exposure to family violence was not only related to mental health problems but also seems to be a risk factor for peer victimization.

Objectives: The present study aimed to examine the prevalence of maltreatment within the family and adolescents' mental health problems and their relation to peer victimization. We also aimed to gain new insights into the perceptions of adolescents concerning maltreatment within their families.

Methods: Data were collected from April to November 2017 in a representative sample of 702 students from 12 public secondary schools in Southwestern Uganda who responded to self-administered questionnaires.

Results: Overall, 95\% of the students experienced at least one type of family violence in the past month. Students $(81.3 \%)$ had endorsed some level of acceptance of violent discipline as a valid strategy in response to any misbehavior. Maltreatment within the family was related to peer victimization $(\beta=.47)$ and this relation was mediated by mental health problems $(0.002,95 \%$ CI: 0.001-0.004).

Conclusions: The results indicated a high prevalence of maltreatment within Ugandan families that was associated with peer victimization. This underscores the need to implement interventions aiming to reduce maltreatment and violence in order to protect children from potentially negative consequences.
\end{abstract}

\section{Introduction}

Families provide children with a private space in which to enjoy comfort, attain growth and receive protection from harm.

\footnotetext{
* Corresponding author at: Department of Psychology, University of Bielefeld, 33501 Bielefeld, Germany.

E-mail addresses: joseph.ssenyonga@uni-konstanz.de (J. Ssenyonga), charles_muwonge2002@hotmail.co.uk (C. Magoba Muwonge), tobias.hecker@uni-bielefeld.de (T. Hecker).
} 
However, many children experience violent discipline and neglect at home (Hillis, Mercy, \& Saul, 2017; UNICEF, 2014). Violent discipline refers to the deliberate application of physical and/or emotional violence to cause physical or emotional pain in an attempt to modify or control the child's behavior (2010, Straus, 2000). Neglectful behavior refers to the failure of caregivers to accomplish their ascribed responsibility to provide and meet the child's development requirements and protect the child from possible harm (Stoltenborgh, Bakermans-Kranenburg, \& Van Ijzendoorn, 2013). Risk factors for child neglect include poverty (Dubowitz, 2007, 2013), parental stress (Mikolajczak, Elena, Avalosse, \& Roskam, 2018; Nkuba, Hermenau, \& Hecker, 2018), psychological problems (Mulder, Kuiper, van der Put, Stams, \& Assink, 2018), impaired parent-child relations, parent's perception of their children as a problem, and other family factors (Stith et al., 2009). In low-resource contexts, child neglect is often unintended (Dubowitz \& Bennett, 2007) but may still result into negative outcomes (Hecker, Boettcher, Landolt, \& Hermenau, 2019; Maguire \& Naughton, 2016).

\subsection{Global prevalence of family violence}

About one billion children worldwide have experienced recurrent physical violence inflicted by their caregivers (Devries et al., 2017; Know Violence in Childhood, 2017; UNICEF, 2014). Approximately 83\% of all children throughout the African continent faced violent disciplinary practices at home (UNICEF, 2016). Family violence has also been documented in East-African families, e.g. in Tanzania (Hecker, Hermenau, Isele, \& Elbert, 2014; Hecker, Hermenau, Salmen, Teicher, \& Elbert, 2016; Nkuba, Hermenau et al., 2018) and in Uganda (African Network for Prevention \& Protection against Child Abuse \& Neglect [ANPPCAN], 2011; Devries et al., 2014, 2015).

Prevalence studies from high-income and low-and-middle income countries indicate high rates of child neglect globally. Prevalence rates of physical and emotional neglect in high-income countries are estimated to be $16.3 \%$ and $18.4 \%$ respectively (Stoltenborgh et al., 2013). About 22.5\% to 43.6\% of children in East Asia and Pacific region (UNICEF, 2012), 31\% to 37\% of children in Tanzania (Hecker et al., 2019; Nkuba, Hermenau et al., 2018) and 38\% to 45\% of children in Uganda (Naker \& Sekitoleko, 2009; Naker, 2005) were at risk of experiencing neglect.

\subsection{Attitudes towards violence}

Violence against children at home may be prevalent because it is still legally acceptable in all settings in 53 (26.6\%) of the 199 countries globally (Gershoff, 2017). Furthermore, the use of violent disciplinary methods is an acceptable practice in some societies (Butchart, Harvey, Mian, \& Fürniss, 2006; Lansford \& Dodge, 2008; UNICEF, 2017). Sociocultural attitudes that favor the use of violent discipline result in higher actual rates of violence against children (Straus, 2010), especially when caregivers believe that its use is necessary (Lansford et al., 2017; Wandera et al., 2017). For example, strong support of violence resulted in higher rates of child maltreatment (Hart, Durrant, Newell, \& Power, 2005). Furthermore, a longitudinal study in nine countries showed that community acceptance of violence predicted parental use of violent discipline (Lansford et al., 2015). Likewise, approval of violent discipline by significant others, including family and friends, and the anticipated positive outcomes attributed to the use of such violence, further reinforced and maintained these positive attitudes towards violent discipline (Taylor, Hamvas, Rice, Newman, \& DeJong, 2011).

Children from societies that permit the use of violence tend to have a different interpretation of its application by significant others. Without a doubt, children dislike the experience of violence but find its use justifiably in certain circumstances, e.g., in response to unacceptable behaviors (Breen, Daniels, \& Tomlinson, 2015; Feinstein \& Mwahombela, 2010). Children who experience parental use of harsh discipline over time internalize that violence is a legitimate option that controls (mis-) behavior. Hence, these children tend to approve the use of violence (Grogan-Kaylor, Ma, \& Graham-Bermann, 2018). In addition, personal experiences of violence in childhood predicts endorsement of the use of violence in child rearing (Douglas, 2006). So far, very little is known about what young people in societies where violence is the norm in child rearing, such as Uganda, actually think about the use of violence in child rearing. In addition, it remains largely unknown, whether the hypothesized positive attitudes towards violent discipline would reduce the association between violent discipline and potential negative consequences, such as mental health problems.

\subsection{Consequences of family violence}

Nonetheless, family violence and violent discipline may result into negative outcomes. For example, violence against children affects the child-caregiver relationship, results in the child's avoidance of parents, and the child's fear of caregivers may hinders effective utilization of their help and support when needed (Breen et al., 2015). A study conducted in Tanzania with adolescents observed that $41 \%$ of the students reported mental health problems. Parental use of physical violence was associated with student's mental health problems (Nkuba, Hermenau, Goessmann, \& Hecker, 2018). Previous studies conducted in East-Africa indicated that harsh punishment was related to negative sequel including internalizing and externalizing problems, cognitive functioning, and poor school performance (Hecker et al., 2014, 2016; Nkuba, Hermenau, \& Hecker, 2019). In Uganda primary school children, exposed to violence did not attend school regularly, had poor mental health, and experienced other forms of violence (Clarke et al., 2016; Devries et al., 2014). The prevalence of violence within the family against adolescents of secondary school age and the association between the experience of violence and negative consequences has largely not been investigated in Uganda to date.

Neglect affects the livelihood of children and is as harmful as other forms of maltreatment (Norman et al., 2012). Failure by the caregivers to use available resources to meet the physical and emotional needs of their children may result in undesirable consequences to the child's moral, physical, and social development (Stoltenborgh et al., 2013). For example, neglected children were 
more likely to suffer from behavioral, cognitive, and internalizing problems (Hildyard \& Wolfe, 2002), and physical and mental health problems (Dubowitz, 2013). The only study that investigated child neglect in a community sample in East Africa suggested that it was associated with mental health problems and that this relation is particularly stronger among younger children (Hecker et al., 2019). More research on the prevalence and the consequences of child neglect in East-Africa is needed.

\subsection{Exposure to family violence increases the risk of peer victimization}

Furthermore, research findings suggest that children who experience violence and maltreatment in one setting are at risk of also experiencing violence in other settings (Chokprajakchat, Kuanliang, \& Sumretphol, 2015; Finkelhor, Ormrod, \& Turner, 2007; Leoschut \& Kafaar, 2017). For instance, family violence at home increased the risk of experiencing peer victimization (Mohr, 2006; Xia, Li, \& Liu, 2018). In addition, this relation was mediated by internalized problem behaviors (Mohr, 2006). This means that adolescents with internalizing problems are particularly likely to be victims of violence in other situations (Markowitz, 2011; Stuart, 2003). In other words, parental victimization makes children more likely to suffer from internalizing problems which may increase the risk for peer victimization. Likewise, the external expression of mental health symptoms, such as exhibiting aggressive or antisocial behaviors are more likely to result in increased peer victimization (Chokprajakchat \& Kuanliang, 2018; Juvonen \& Graham, 2014). Thus, internalizing and externalizing behavioral problems increase the risk for peer victimization (Arseneault, Bowes, \& Shakoor, 2010). Other personal characteristics, such as low self-esteem, social anxiety, loneliness, self-blame and negative affect, may also increase the odds of being victimized (Graham \& Bellmore, 2007).

This so-called poly-victimization is assumed to also be highly prevalent in societies with positive attitudes towards violence (Benedini, Fagan, \& Gibson, 2016; Cook, Williams, Guerra, Kim, \& Sadek, 2010) and often results into negative squeal (Adams et al., 2016; Kamndaya et al., 2017; Le, Holton, Romero, \& Fisher, 2018). So far, however, very little is known about the link between family violence, and peer victimization among African youth.

\subsection{Objectives}

Little is known about the prevalence of family violence and neglect among adolescents in Sub-Saharan Africa in general and in Uganda in particular (Stoltenborgh, Bakermans-Kranenburg, Alink, \& van Ijzendoorn, 2015). Further, in the Ugandan context, data on the extent and consequences of family violence and neglect exist only for primary school children (Clarke et al., 2016; Devries et al., 2014; Thumann, Nur, Naker, \& Devries, 2016). Therefore, the first aim of the present study was to examine the prevalence of family violence and neglect, as well as of adolescents' mental health and peer victimization in a representative sample of students from public secondary schools in Southwestern Uganda. Based on past prevalence studies in the neighboring country of Tanzania (Nkuba et al., 2018; Nkuba, Hermenau et al., 2018), we expected a high prevalence of physical and emotional violence, neglect, peer victimization, and mental health problems among adolescents of secondary school age.

Since very little is known about what young people actually think about violence in child rearing and whether this has an impact on the potential consequences of family violence, such as mental health problems, the second aim was to gain new insight into the perceptions and views of Ugandan youth about violent discipline in their families and their relation to mental health problems.

As previous studies have shown that exposure to violence was associated with both mental health problems (e.g., Brown et al., 2009) and peer victimization (Finkelhor et al., 2007), the third aim of this study was to investigate the associations between maltreatment within the family, mental health problems, and peer victimization. Consistent with previous studies (e.g., Mohr, 2006; Xia et al., 2018) we hypothesized positive associations of maltreatment at home with both mental health problems and peer victimization. In addition, we predicted that the relation between maltreatment at home and peer victimization would be mediated by adolescents' mental health problems.

\section{Methods}

\subsection{Design and sampling}

The study was conducted in Ankole region Southwestern Uganda. We selected this region purposively because it has the third highest secondary school enrollment in Uganda. The region has 10 districts from which we randomly selected five districts. Mbarara district was purposively included in the sample because this locality has the highest number of secondary schools (Education Planning \& Policy Analysis Department Ministry of Education Science Technology \& Sports, 2014). The sample comprised of 12 public secondary schools selected from six districts.

Ordinary level or lower secondary school education takes four years that is from the $8^{\text {th }}$ year to the $11^{\text {th }}$ year of formal schooling. Ankole region had a total of 116, 943 students ( $51 \%$ female) enrolled at ordinary level, with $53.7 \%$ of the students studying in the $8^{\text {th }}$ and $9^{\text {th }}$ year of formal schooling. Only students in their $8^{\text {th }}$ and $9^{\text {th }}$ year of schooling were included in the sample. To ensure that our sample is representative of Ankole region, we randomly selected the schools and the students. From each school we selected 60 students that is 30 students in the $8^{\text {th }}$ year and 30 students studying in the $9^{\text {th }}$ year of secondary education. We used stratified sampling to select 15 boys and 15 girls in each class or stream. The study data were collected from April to November 2017. 


\subsection{Procedure and data assessment}

Ethical clearance was obtained from the Research Ethics Committee of Mbarara University of Science and Technology, Ugandan National Council of Science and Technology, and the Ethics Review Board of the University of Konstanz, Germany. Data were collected by one Ugandan researcher and two research assistants who were previously trained in data collection methods. Parental consent as well as students' assent were sought before students were accepted to participate in the study. Students took about 25-30 min to fill the anonymous self-administered questionnaire in groups of three to five. Members of the research team were present to address any questions during the administration. The sample comprised of 702 students, giving a response rate of $97.5 \%$ (702 of 720). Other aspects of the data gathered during the investigations are presented by Ssenyonga, Hermenau, Nkuba and Hecker (2019).

\subsection{Participants}

The sample included 702 students (50\% female) between the ages of 12 and 17 years $(M=15.5, S D=1.15)$. In total, 53.4\% $(n=375)$ of the students were in their $8^{\text {th }}$ year of formal schooling. The majority $(98.7 \%, n=693)$ reported that one or both biological parents were alive, that they lived together with them in the same household $(84.9 \%, \mathrm{n}=596)$, and that the parent(s) provided them with emotional $(88.7 \%, \mathrm{n}=632)$ and financial support $(88.9 \%, \mathrm{n}=624)$.

\subsection{Measures}

Students in Uganda use English as the medium of instruction throughout the educational cycle. Therefore, the questionnaires were administered in English. First the questionnaire elicited socio-demographic information such as age, gender and class.

Students' exposure to violence and maltreatment within the family was assessed by the Conflict Tactics Scale Parent-Child (CTSPC; Straus, 2007). CTSPC assessed students' exposure to physical violence (13-items), emotional violence (5-items), and neglect (7-items). In addition, two items were added to the neglect subscale, e.g., how often in the past month have your parents, relatives or guardians had no time to play with you? Items are scored on a scale ranging from never (0) to more than 20 times (25). Sum scores for physical violence ranged from 0 to $325,0-125$ for emotional violence, $0-175$ for neglect, and 0 to 450 for the total family violence score. The original CTSPC Cronbach alpha coefficients were low to moderate. We used the CTSPC because of its good cross-cultural reliability and validity (Cui, Xue, Connolly, \& Liu, 2016) and because it has been used in comparable studies in East Africa (Hecker, Goessmann, Nkuba, \& Hermenau, 2018; Nkuba et al., 2018; Nkuba, Hermenau et al., 2018). Cronbach's alpha coefficient for the CTSPC total score in the current sample was .82.

Students' attitudes towards violent discipline was assessed using an adapted version of the CTSPC with a 13-item physical violence subscale and a 5-item emotional violence subscale (Nkuba, Hermenau, Goessmann, \& Hecker, 2018). Items are rated on a 4point scale ranging from never ok (0) to always ok (3). The sum of the 18 items (range 0-54) provide the total score of positive attitudes towards violent discipline. The reliability coefficient for the current sample was .85 for the total score.

The 25-item self-report Strength and Difficulties Questionnaire (SDQ) was used to measure students' mental health problems and included five subscales: prosocial behavior, conduct problems, peer problems, emotional problems, and hyperactivity. The subscales have five items each and were answered on a 3-point Likert scale from not true (0), somehow true (1) and certainly true (2) to provide a score ranging from 0 to 10 . The cutoff score of 6 on the emotional problem subscale, 4 on the conduct problem subscale, 6 on the hyperactivity subscale, and 3 on the peer problems subscale indicated the presence of mental health problems in that particular scale domain. Sum scores of the four problems subscales provided the total difficulty score (range: 0 to 40 ), with scores of 17 and higher indicating the presence of mental health problems (Goodman, Meltzer, \& Bailey, 1998). The SDQ has been used frequently and with good validity and reliability in a number of studies in the African context (Hecker et al., 2016, 2019; Hoosen, Davids, de Vries, \& Shung-King, 2018; Nkuba et al., 2018; Thumann et al., 2016). The SDQ total score had a reliability of .63 in the current study. The heterogeneity of the total score, including internalizing and externalizing problems, may explain the moderate level of Cronbach's Alpha coefficient.

To assess peer victimization we used the 5-item peer victimization subscale of the Maltreatment and Abuse Chronology of Exposure (MACE; Teicher \& Parigger, 2015). Sample items asked included: 'How often in the past month has any adolescent of your own age or older excluded you from groups activities?' or '...hit you so hard that you were injured?' The answer categories were identical to the categories of the CTSPC ranging from 'never' (0) to 'more than 20 times' (25), referring to the past month. Sum scores for the scale ranged from $0-125$. The original MACE peer victimization scale had a test-retest reliability of .75. The reliability coefficient for the current sample was .66 for the total score. The small number of items may explain the moderate level of Cronbach's Alpha coefficient.

\subsection{Data analysis}

We used descriptive statistics to present the prevalence rates of exposure to maltreatment within the family (physical and emotional violence, neglect), peer victimization, and mental health problems. Chi-square tests were used to test for potential gender differences. Prevalence on item level (e.g., different forms of maltreatment) are presented in the Supplementary Tables 1-3. Cases with one or more missing values were excluded from the respective analyses (in total $n=15$ ). All intercorrelations are displayed in Supplementary Table 4. We utilized linear regression models to examine specific associations between maltreatment and violence, 
attitudes towards violent discipline, peer victimization, and mental health. We conducted simple mediation analyses following the heuristic of Baron and Kenny (1986): a variable would be considered a mediator if (1) the independent variable would be significantly related to the dependent variable, (2) the independent variable would significantly correlate with the mediator, and (3) the mediator would be significantly associated with the dependent variable controlling for the independent variable. To test significance of the indirect effect and to estimate effect-sizes, we used the Sobel test as well as a nonparametric approach using 10,000 bootstraps (Preacher \& Hayes, 2004). The regression models fulfilled the necessary criteria for linear regression analyses: the residuals did not deviate significantly from normality, linearity, and homoscedasticity. All analyses used a two-tailed $\alpha=.05$. Our metric for a small effect size was $\mathrm{f}^{2} \geq 0.02$, for a medium effect $\mathrm{f}^{2} \geq 0.15$, and for a large effect $\mathrm{f}^{2} \geq 0.35$ (Cohen, 1992). Data were analyzed with IBM SPSS Statistics Version 25 for MAC.

\section{Results}

\subsection{Maltreatment at home}

Overall, 663 students $(95 \%, \mathrm{n}=698)$ reported having experienced at least one type of violent act at home in the past month. There were no significant gender differences $\left(\chi^{2}(1)=0.04, p=.85\right)$. In the present study, 83.6\% $(n=585)$ of the students had experienced at least one type of physical violence at home in the past month. Again, we did not find any gender differences $\left(\chi^{2}\right.$ $(1)=0.51, \mathrm{p}=.48)$. Slapping on the hand, arm or leg (48.9\%), slapping on the buttocks or bottom with a bare hand (43.9\%), and slapping the face, head or ears (40.2\%) ranked as the most commonly experienced forms of physical violence. In total, $86.1 \%$ ( $n=603$ ) of the students experienced at least one form of emotional violence at home in the past month, with common forms of emotional violence including being shouted, yelled or screamed at by their parents (49.8\%), threats of being spanked (46.6\%), and being called dumb, lazy or other bad names by their parents $(42.4 \%)$, respectively. No gender differences were detected $\left(\chi^{2}\right.$ (1) $=0.13, \mathrm{p}=.72$ ).

Regarding child neglect, 79.2\% $(\mathrm{n}=552)$ of the students had experienced at least one type of neglect in the past month. Again, we did not find any gender differences $\left(\chi^{2}(1)=1.91, \mathrm{p}=.17\right)$. About $43 \%(\mathrm{n}=302)$ of the students stayed with caregivers who had no time to play or interact with them, $34.2 \%(n=240)$ of the caregivers had no interest to listen and talk to the students, while 239 students (34.1\%) reported staying with caregivers who were so caught up with their own problems that they could not show or tell them that they loved them (for more details see Supplementary Table 1).

\subsection{Students' attitudes towards violent discipline}

The majority of students $(81.3 \%, \mathrm{n}=568)$ had endorsed some level of acceptance of violent discipline (i.e., reporting "rarely okay" or "usually okay" on one or more items). In total, $84 \%$ of the male and $79 \%$ of the female adolescent students reported positive attitudes towards violent discipline. The level of acceptance of violent discipline did not differ between the two genders $\left(\chi^{2}\right.$ $(1)=3.46, p=.06)$. In total, $72.7 \%(n=509)$ of the students felt that it was alright for them to be punished using physical violent methods in the event they do something wrong at home (see Supplementary Table 2), for instance being spanked on the bottom with bare hands (41.9\%), slapped on the hand, arm or leg (41.7\%) or hitting their bottom with a ruler, belt, stick or some other hard object (27.2\%). In case of any misbehavior, 478 students (68.2\%) had endorsed some level of acceptance of their parents' utilization of emotional violence, such as saying that they would be sent out of the house for some time (41.7\%), threats of being spanked (37.5\%) and being called dumb, lazy or other names (30.7\%). There was no significant difference in regard to the level of acceptance of physical violence $\left(\chi^{2}(1)=0.58, \mathrm{p}=.45\right)$. However, the level of acceptance of emotional violence differed significantly between male $(72 \%)$ and female $(65 \%)$ adolescent students $\left(\chi^{2}(1)=4.22, \mathrm{p}=.04\right)$.

\subsection{Prevalence of students' mental health problems}

Sixty students (8.5\%) had generally higher levels of mental health problems. There were no gender differences in the prevalence of mental health problems $\left(\chi^{2}(1)<0.01, \mathrm{p}>\right.$.99). Specifically, 43.2\% $(\mathrm{n}=303)$ of the students had peer problems, $15.8 \%$ $(n=111)$ experienced emotional symptoms, $14.4 \%(n=100)$ had high levels of conduct problems and $2.6 \%(n=18)$ had elevated levels of hyperactivity. There were no gender differences on subscale level, except for emotional problems. Female adolescents (19\%) reported a significantly higher prevalence rate compared to male adolescents $\left(13 \% ; \chi^{2}(1)=4.72, p=.03\right)$.

\subsection{Association between violent discipline, attitudes towards violent discipline, and mental health problems}

Violent discipline was positively correlated with mental health problems $(r=.19, \mathrm{p}<.001)$. After controlling for gender and age, violent discipline and positive attitudes towards violent discipline were significantly related to adolescents' mental health problems (see Table 1). The regression model explains $5 \%$ of the variability of mental health problems. Without controlling for attitudes towards discipline, violent discipline was significantly associated to mental health problems (Table 1). This regression model explained $3 \%$ of the variability of mental health problems. Furthermore, violent discipline was significantly associated with positive attitudes towards violent behavior (Table 1 ). This model explained $3 \%$ of the variability of the mental health problems. To investigate whether the association between violent discipline and mental health problems is mediated by positive attitudes towards violent discipline, we conducted a test for simple mediation (Preacher \& Hayes, 2004), with violent discipline as the independent 
Table 1

Associations between violent discipline by parents, attitudes towards violent discipline and mental health problems in a mediated regression model.

\begin{tabular}{|c|c|c|c|c|}
\hline & B & SE of $B$ & $\beta$ & $\mathrm{T}$ \\
\hline \multicolumn{5}{|l|}{ Attitudes towards discipline ${ }^{a}$} \\
\hline Violent discipline & 0.03 & .01 & .16 & $4.18^{* * *}$ \\
\hline Gender & -0.44 & .021 & -.03 & -0.85 \\
\hline Age & 0.25 & .04 & .04 & 1.12 \\
\hline \multicolumn{5}{|l|}{ Mental health problems ${ }^{\mathrm{b}}$} \\
\hline Violent discipline & 0.02 & .01 & .16 & $4.26^{* * *}$ \\
\hline Gender & 0.15 & .30 & .02 & 0.51 \\
\hline Age & 0.19 & .13 & .06 & 1.51 \\
\hline \multicolumn{5}{|l|}{ Mediation model } \\
\hline \multicolumn{5}{|l|}{ Mental health problems ${ }^{c}$} \\
\hline Violent discipline $^{\mathrm{d}}$ & 0.01 & .01 & .14 & $3.58^{* * k}$ \\
\hline Attitudes towards discipline & 0.08 & .02 & .14 & $3.76^{* * *}$ \\
\hline Gender & 0.21 & .29 & .03 & 0.72 \\
\hline Age & 0.17 & .13 & .05 & 1.36 \\
\hline Indirect effect ${ }^{\mathrm{e}}$ & Unstandardized estimates & SE of $B$ & Standardized estimates & $\mathrm{z}$ \\
\hline Family violence $\rightarrow$ Mental health problems & 0.01 & 0.01 & .02 & $2.75^{* *}$ \\
\hline
\end{tabular}

Note. $\mathrm{N}=695$, B: unstandardized regression weight, SE: standard error, $\beta=$ standardized regression weight, $\mathrm{T}$ : $t$-test statistics.

$* * \mathrm{p} \leq .01$ two-tailed.

$* * * \mathrm{p} \leq .001$ two-tailed.

${ }^{\mathrm{a}}$ Adj. $\mathrm{R}^{2}=.03 ; \mathrm{F}(3,691)=6.68, \mathrm{p}=.002, \mathrm{f}^{2}=0.03$

${ }^{\mathrm{b}}$ Adj. $\mathrm{R}^{2}=.03 ; \mathrm{F}(3,691)=6.76, \mathrm{p}=.002, \mathrm{f}^{2}=0.03$

${ }^{c}$ Adj. $\mathrm{R}^{2}=.05 ; \mathrm{F}(4,690)=8.70, \mathrm{p}<.001, \mathrm{f}^{2}=0.05$.

$\mathrm{d}$ Total effect of the level of violent discipline on mental health problems: $B=0.02$, SE of $B=0.01, \beta=.16$.

e Sobel test result for the indirect effect of the level of violent discipline on mental health problems via the mediator attitudes towards violent discipline.

variable, positive attitudes towards violent discipline as the mediator and mental health problems as the dependent variable. When attitudes were added as a mediator, the association between violent discipline and mental health problems was reduced, this reduction was significant $(\mathrm{Z}=2.75, \mathrm{p}=.006$, Bootstrap results: 0.02, SE: 0.01, 95\%-CI: $0.01-0.04)$. In other words, student-reported experience of violent discipline was associated with mental health problems and positive attitudes towards violent discipline. Positive attitudes partially mediated the association between violent discipline and mental health problems.

\subsection{Peer victimization experienced by students}

In total, 74.5\% $(n=521)$ of the students experienced at least one form of peer victimization in the past month. There were no significant gender differences $\left(\chi^{2}(1)<0.01, \mathrm{p}=.98\right)$. The most common forms of peer victimization included being called names or hurtful thing (46.4\%), exclusion from activities or groups (39\%), and saying things behind one's back, posting derogatory messages, or spread rumors $(36.6 \%)$, respectively (see Supplementary Table 3 ).

\subsection{Association between maltreatment within the family, mental health problems and peer victimization}

Maltreatment within the family was positively correlated with peer victimization $(\mathrm{r}=.49, \mathrm{p}<.001)$. After controlling for gender and age, maltreatment within the family and adolescents' mental health problems were significantly related to peer victimization (see Table 2). The regression model explains $26 \%$ of the variability of peer victimization. Without controlling for mental health problems, maltreatment was significantly associated to peer victimization (Table 2). This regression model explained $24 \%$ of the variability of peer victimization. Furthermore, maltreatment was significantly associated with adolescents' mental health problems (Table 2). This model explained only $4 \%$ of the variability of the mental health problems. To investigate whether the association between maltreatment within the family and peer victimization is mediated by mental health problems, we conducted a test for simple mediation (Preacher \& Hayes, 2004), with maltreatment as the independent variable, mental health problems as the mediator and peer victimization as the dependent variable (see Fig. 1). When mental health problems were added as a mediator, the association between maltreatment and peer victimization was reduced, this reduction was significant $(\mathrm{Z}=2.90, \mathrm{p}=.004$, Bootstrap results: 0.02 , SE: $0.01,95 \%$-CI: 0.01 - 0.04). In other words, student-reported experience of maltreatment within the family was associated with peer victimization and mental health problems, and mental health problems partly mediated the association with peer victimization (see Fig. 1). In an additional multiple regression analysis, we checked for differential relations between different maltreatment subtypes. However, we found that all assessed types of maltreatment (i.e., physical violence, emotional violence, and neglect) were positively related to peer victimization (see Supplementary Table 5 for more details). 
Table 2

Associations between maltreatment by parents, mental health problems and peer victimization in a mediated regression model.

\begin{tabular}{|c|c|c|c|c|}
\hline & B & $\mathrm{SE}$ of $\mathrm{B}$ & $\beta$ & $\mathrm{T}$ \\
\hline \multicolumn{5}{|l|}{ Mental health problems ${ }^{a}$} \\
\hline Maltreatment & 0.02 & 0.01 & .19 & $5.15^{* * *}$ \\
\hline Gender & 0.16 & 0.29 & .02 & 0.53 \\
\hline Age & 0.15 & 0.13 & .04 & 01.14 \\
\hline \multicolumn{5}{|l|}{ Peer victimization ${ }^{\mathrm{b}}$} \\
\hline Maltreatment & 0.05 & 0.01 & .50 & $14.87^{* * *}$ \\
\hline Gender & -0.04 & 0.32 & -.01 & -0.13 \\
\hline Age & -0.18 & 0.14 & -.04 & -1.26 \\
\hline \multicolumn{5}{|l|}{ Mediation model } \\
\hline \multicolumn{5}{|l|}{ Peer victimization ${ }^{\mathrm{c}}$} \\
\hline Maltreatment ${ }^{\mathrm{d}}$ & 0.05 & 0.01 & .47 & $14.04 * * *$ \\
\hline Mental health problems & 0.15 & 0.04 & .12 & $3.58^{* * *}$ \\
\hline Gender & -0.06 & 0.32 & -.01 & -0.19 \\
\hline Age & -0.20 & 0.14 & -.05 & -1.43 \\
\hline Indirect effect ${ }^{\mathrm{e}}$ & Unstandardized estimates & $\mathrm{SE}$ of $\mathrm{B}$ & Standardized estimates & $\mathrm{Z}$ \\
\hline Maltreatment $\rightarrow$ Mental health problems & 0.01 & 0.01 & .02 & $2.61^{* *}$ \\
\hline
\end{tabular}

Note. $\mathrm{N}=689$, B: unstandardized regression weight, SE: standard error, $\beta=$ standardized regression weight, $\mathrm{T}$ : $t$-test statistics.

$* * \mathrm{p} \leq .01$ two-tailed.

$* * * \mathrm{p} \leq .001$ two-tailed.

${ }^{a}$ Adj. $\mathrm{R}^{2}=.04 ; \mathrm{F}(3,686)=9.58, \mathrm{p}<.001, \mathrm{f}^{2}=0.04$

${ }^{\mathrm{b}}$ Adj. $\mathrm{R}^{2}==.24 ; \mathrm{F}(3,686)=73.75, \mathrm{p}<.001, \mathrm{f}^{2}=0.32$.

${ }^{\text {c }}$ Adj. $\mathrm{R}^{2}=.26 ; \mathrm{F}(4,685)=59.47, \mathrm{p}<.001, \mathrm{f}^{2}=0.35$

${ }^{d}$ Total effect of the level of family violence on peer victimization: $B=0.05$, SE of $B=0.01, \beta=.50$.

${ }^{\mathrm{e}}$ Sobel test result for the indirect effect of the level of maltreatment within the family on peer victimization via the mediator mental health problems.

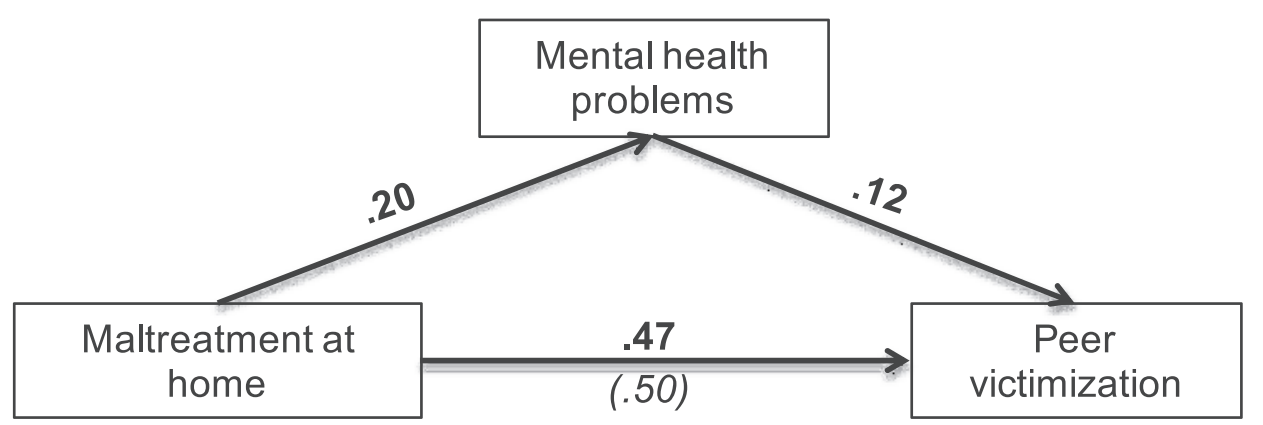

Fig. 1. Mediated regression model $(\mathrm{N}=689)$ exploring the mediating influence of mental health probems on the relation between family violence and peer victimization while controlling the influence of adolescents' age and gender. This model is consistent with the view that the relation between family violence and peer victimization is partially mediated by adolescents' mental health problems. Standardized regression weights are depicted; all associations are significant beyond .05.

\section{Discussion}

\subsection{Prevalence of violence and neglect}

Altogether, 95\% of the students had experienced family violence in the past month. Our findings are in concordance with previous findings from East-Africa and elsewhere that documented high prevalence rates of child maltreatment (Know Violence in Childhood, 2017; Stoltenborgh et al., 2015; UNICEF, 2014). However, our study contributes novel and important findings with regard to adolescents in Uganda. Additionally, our results are also in agreement with previous studies that demonstrated that the prevalence of physical and emotional violence is comparable. Often physical and emotional violence occur together (Clarke et al., 2016; Nkuba, Hermenau, Goessmann, et al., 2018a; Nkuba, Hermenau et al., 2018; UNICEF, 2012, 2014). Our results support the notion that perpetuators of violence are caregivers who are known to the child (Devries et al., 2017; Pinheiro, 2006) who use their authority, and resort to violent discipline as a means of controlling the child's behavior.

Neglect had a high prevalence rate in the current study (79.2\%). This finding is in agreement with previous studies (Hecker et al., 2019; Naker, 2005; Nkuba, Hermenau et al., 2018). The high levels of neglect in the current study can be explained partly by the parents' lack of adequate resources (Mcsherry, 2007) to provide for all of their children's needs, given that most students acknowledged parental emotional (88.7\%) and financial support (88.9\%). Hence, neglect can be assumed to be highly prevalent in lowand middle-income countries partly due to socioeconomic conditions (UNICEF, 2014), where parents not only neglect their own wellbeing and grapple with challenging daily realities but also neglect their children (Dubowitz, 2007, 2013). However, parents may not 
be knowledgeable regarding the potential effects of neglecting their children (Mcsherry, 2007). As neglect has received very little attention globally and particularly in Africa so far, the results of our current study emphasize the necessity of advancing research on neglect as one specific type of maltreatment. Yet, assessing something that is absent is complex and challenging compared to (visible) acts of violence and abuse. Therefore, instruments measuring neglect still require improvement, particularly for assessing neglect in low-resource settings.

\subsection{Adolescents' attitudes towards violent discipline}

Students reported positive attitudes towards violence and reasonably accept its use in some situations (see Supplementary Table 2). Results of the present study converge with previous findings which found that in societies that legally accept the use of violence and in which the use of violence is normative, children reported positive attitudes towards the application of violence and approved the use of violent disciplinary methods (Breen et al., 2015; Chokprajakchat et al., 2015; Grogan-Kaylor et al., 2018). This may correspond with other findings that found that personal experiences of violence in childhood were related to the approval of disciplinary violence as normal and acceptable (Hart et al., 2005). These findings are of crucial importance because, as we consider the perspectives of the young people concerned, we gain insight into the fact that young people who grow up in violent environments do not question violence in education. This normalization of violent parenting creates a serious barrier in efforts aiming to achieve social changes towards non-violent child rearing practices.

\subsection{Prevalence of mental health problems}

We found a prevalence rate of mental health problems of $8.5 \%$ in the past month. Previous studies in Sub-Saharan African noted higher prevalence of mental health problems among secondary school students (Nkuba, Hermenau, Goessmann, et al., 2018a) and primary school pupils (2016, Clarke et al., 2016; Devries et al., 2014; Hecker et al., 2014). The lower prevalence may be explained in part by the time frame of the study. We screened for mental health problems in the past month compared to a period of the past six months used in the other studies. Our finding that students are more likely to report peer problems is consistent with previous studies (Nkuba et al., 2018; UNICEF, 2014).

\subsection{Association between violent discipline, attitudes towards discipline, and mental health problems}

In accordance with previous studies conducted in East-Africa, we also found that violent discipline was related to mental health problems (Hecker et al., 2014, 2016; Nkuba et al., 2019). Furthermore and in agreement with prior findings (Grogan-Kaylor et al., 2018), we found that violent discipline was also positively related with positive attitudes towards violent discipline among children. These findings support the notion that when societies accept the use of violence, then children raised in such communities will accept and rationalize the use of violence especially as a disciplinary strategy (Breen et al., 2015; Feinstein \& Mwahombela, 2010; GroganKaylor et al., 2018). Surprisingly, positive attitudes towards violent discipline were positively associated with mental health problems. This finding does not support the notion that adolescents in communities that deem such practices to be socially acceptable and legal and who themselves support it would find the effects to be less harmful than those living in societies in which such practices are unacceptable or illegal (Ellison \& Bradshaw, 2009). Nevertheless, the effects as well as the proportion of explained variance were small which limits the significance of our findings. Nonetheless, the low prevalence of mental health problems and the small effects do also not necessarily mean that violence does not affect children as the onset of mental health problems caused or fostered by the use of violent disciplinary strategies may also surface in the long-term, in late adolescence or adulthood for example.

\subsection{Prevalence of peer victimization}

Over $74.5 \%$ of the students had experienced peer victimization in the past month, an indication that apart from parents, peers were also perpetrators of violence. It was previously noted that violence against students is perpetuated mainly by parents and peers, and the present study is in line with those findings (Clarke et al., 2016; Devries et al., 2017). Students in our study experienced violence in diverse settings, and those sources of violence were often co-occurring yet instigated by several perpetuators. Previous studies in Uganda, however, provided lower prevalence rates of peer victimization where $21 \%$ of the students reported experiences of peer victimization in the past week (Thumann et al., 2016) and 47\% of the students had experienced peer victimization at some point in their lifetime (Wandera et al., 2017). In the present study, the prevalence might have been higher, because the sample included secondary school students (12-17 years) who responded to a written questionnaire compared to other studies that included primary school pupils (11-14 years) who provided responses during a face-to-face interview. It is possible that participants in the present study were more likely to disclose this sensitive information compared to participants in studies using face-to-face interviews (Hart et al., 2005).

\subsection{Associations between maltreatment, mental health problems and peer victimization}

We found significant associations between maltreatment within the family, mental health problems, and peer victimization. Both maltreatment and adolescents' mental health problems were associated with peer victimization (see Table 2). Moreover, the effect of maltreatment on peer victimization was mediated by students' mental health problems (see Fig. 1). Our results correspond with 
previous studies which demonstrated that the experience of maltreatment was linked to poor mental health (Brown et al., 2009; Devries et al., 2014; Nkuba, Hermenau, Goessmann, et al., 2018a; Norman et al., 2012; Pinheiro, 2006). Also, the findings converge with studies that assessed the association between maltreatment by peers and mental health (Clarke et al., 2016; Lereya, Copeland, Costello, \& Wolke, 2015; Pinheiro, 2006; Wandera et al., 2017). In addition, our results showed an association between maltreatment at home and peer victimization. This finding supports previous assertions that maltreatment in one setting can easily spill over to other contexts, or the reality that at times violence can occur simultaneously in multiple contexts (Straus, 2010), while also supporting the re-victimization and poly-victimization hypotheses (Cook et al., 2010; Finkelhor et al., 2007; Finkelhor, Ormrod, Turner, \& Holt, 2009; Finkelhor, Shattuck, Turner, Ormrod, \& Hamby, 2011; Lereya, Samara, \& Wolke, 2013; Turner, Finkelhor, \& Ormrod, 2010).

\subsection{Practical and social implications}

Our study results indicated that there was a high prevalence of child neglect, physical and emotional violence, as well as peer victimization among students in Southwestern Uganda. Therefore, there is a high need to implement interventions that aim at reducing maltreatment at home. Preventative interventions, such as the positive parenting program Triple P (Sanders, 2012), have proven effective in reducing violence and maltreatment and improving communication within families. Initial successes have already been seen in comparable settings in East Africa, e.g. in Kenya (De Graaf, Speetjens, Smit, De Wolff, \& Tavecchio, 2008; Haslam et al., 2011). Furthermore, comprehensive approaches that reduce peer victimization and foster better relations among peers and ideally also inside families are very important to be implemented and scientifically tested (Card \& Hodges, 2008). School-based programs, such as the Good-School-Kit (Devries et al., 2015), offer the opportunity to take up the topic of violence among peers and thus offer an important contribution to the prevention of peer violence. Further, efforts should be made to raise awareness of the negative sequels of family violence and peer victimization, and how family violence is associated to violence in other settings. Besides, we need to ensure that the legal regimes that protect children against violence are easily translated into practice, and efforts changing attitudes and behavior towards violence are implemented and sustained (United Nations, 2016).

\subsection{Limitations}

Although the present study has a number of strengths, including the representative sample and utilization of measures that have been previously used in comparable studies in East Africa, it is important to also note some limitations: data were collected using selfreport questionnaires that are prone to social desirability and bias. Further, causality cannot be inferred since the study adopted a cross-sectional design. Generalizability of the study findings to other school settings, for instance privately-owned secondary schools in Uganda, may not be possible because the study sample was limited to only government-aided secondary schools in Southwestern Uganda. Our models only explain a quarter of the variability in the peer victimization scores and only a very small proportion of the variance of the mental health problems score. This fact suggests that other factors that we did not assess in our study play an important role in understanding why children are victimized by peers and why they develop mental health problems.

\section{Conclusions}

The current study highlights the high prevalence of physical and emotional violence, neglect, and peer victimization among school-attending adolescents in Uganda. Additionally, the study showed that the relation between maltreatment within the family and peer victimization was mediated by mental health problems. In sum, we argue that there is a strong need to design and implement interventions that prevent violence and maltreatment in families while at the same time contribute to changing sociocultural beliefs in relation to maltreatment and violence.

\section{Funding}

This research was supported by the Alexander von Humboldt-Foundation and Young Scholar Fund of the University of Konstanz. The funders did not influence the study design, data collection, analysis and interpretation of the data, or the preparation of the manuscript, writing, or decision to submit publish this manuscript for publication.

\section{Declaration of Competing Interest}

None.

\section{Acknowledgements}

We are grateful to the students, teachers, and school administration for their support during this study. The authors would like to thank Thomas Elbert for his tremendous support and supervision and Justin Preston for proof reading the manuscript. Joseph Ssenyonga is grateful to the Alexander von Humboldt Foundation for funding his Postdoctoral fellowship at the University of Konstanz. 


\section{References}

Adams, Z. W., Moreland, A., Cohen, J. R., Lee, R. C., Hanson, R. F., Danielson, C. K., ... Briggs, E. C. (2016). Polyvictimization: Latent profiles and mental health outcomes in a clinical sample of adolescents. Psychology of Violence, 6(1), 145-155. https://doi.org/10.1186/s40945-017-0033-9.

African Network for Prevention and Protection against Child Abuse and Neglect [ANPPCAN] (2011). A situation analysis of child abuse and neglect in Uganda. 2011. Kampala: Author.

Arseneault, L., Bowes, L., \& Shakoor, S. (2010). Bullying victimization in youths and mental health problems: 'Much ado about nothing'? Psychological Medicine, 40(5), 717-729. https://doi.org/10.1017/S0033291709991383.

Baron, R. M., \& Kenny, D. A. (1986). The moderator-mediator variable distinction in social psychological research. Journal of Personality and Social Psychology, 51(6), 1173-1182. https://doi.org/10.1037/0022-3514.51.6.1173.

Benedini, K. M., Fagan, A. A., \& Gibson, C. L. (2016). The cycle of victimization: The relationship between childhood maltreatment and adolescent peer victimization. Child Abuse \& Neglect, 59, 111-121. https://doi.org/10.1016/j.chiabu.2016.08.003.

Breen, A., Daniels, K., \& Tomlinson, M. (2015). Children's experiences of corporal punishment: A qualitative study in an urban township of South Africa. Child Abuse \& Neglect, 48, 131-139. https://doi.org/10.1016/j.chiabu.2015.04.022.

Brown, D. W., Riley, L., Butchart, A., Meddings, D. R., Kann, L., \& Harvey, A. P. (2009). Exposure to physical and sexual violence and adverse health behaviours in African children: Results from the global school-based student health survey. Bulletin of the World Health Organization, 87(6), 447-455. https://doi.org/10.2471/ BLT.07.047423.

Butchart, A., Harvey, A. P., Mian, M., \& Fürniss, T. (2006). Preventing child maltreatment: A guide to taking action and generating evidence. Genève: World Health Organization \& International Society for Prevention of Child Abuse and Neglect.

Card, N. A., \& Hodges, E. V. E. (2008). Peer victimization among schoolchildren: Correlations, causes, consequences, and considerations in assessment and intervention. School Psychology Quarterly, 23(4), 451-461. https://doi.org/10.1037/a0012769.

Chokprajakchat, S., \& Kuanliang, A. (2018). Peer victimization : A review of literature. International Journal of Criminal Justice Sciences, 13(1), 98-111. https://doi.org/ 10.5281 /zenodo.1403396.

Chokprajakchat, S., Kuanliang, A., \& Sumretphol, N. (2015). What children say about violence, victimization, and punishment. Journal of Ethnicity in Criminal Justice, 13(4), 309-329. https://doi.org/10.1080/15377938.2014.997951.

Clarke, K., Patalay, P., Allen, E., Knight, L., Naker, D., \& Devries, K. (2016). Patterns and predictors of violence against children in Uganda: A latent class analysis. BMJ Open, 6, e010443. https://doi.org/10.1136/bmjopen-2015-010443.

Cohen, J. (1992). A power primer. Psychological Bulletin, 112(1), 155-159. https://doi.org/10.1037/0033-2909.112.1.155.

Cook, C. R., Williams, K. R., Guerra, N. G., Kim, T. E., \& Sadek, S. (2010). Predictors of bullying and victimization in childhood and adolescence: A meta-analytic investigation. School Psychology Quarterly, 25(2), 65-83. https://doi.org/10.1037/a0020149.

Cui, N., Xue, J., Connolly, C. A., \& Liu, J. (2016). Does the gender of parent or child matter in child maltreatment in China? Child Abuse \& Neglect, 54, 1-9. https://doi. org/10.1016/j.chiabu.2016.01.003.

De Graaf, I., Speetjens, P., Smit, F., De Wolff, M., \& Tavecchio, L. (2008). Effectiveness of the Triple P-positive parenting program on parenting: A meta-analysis. Family Relations, 57(5), 553-566. https://doi.org/10.1111/j.1741-3729.2008.00522.x.

Devries, K. M., Child, J. C., Allen, E., Walakira, E., Parkes, J., \& Naker, D. (2014). School violence, mental health, and educational performance in Uganda. Pediatrics, 133(1), e129-e137. https://doi.org/10.1542/peds.2013-2007.

Devries, K. M., Knight, L., Child, J. C., Mirembe, A., Nakuti, J., Jones, R., ... Naker, D. (2015). The Good School Toolkit for reducing physical violence from school staff to primary school students: A cluster-randomised controlled trial in Uganda. The Lancet Global Health, 3(7), e378-e386. https://doi.org/10.1016/S2214-109X(15) 00060-1.

Devries, K. M., Knight, L., Petzold, M., Merrill, K. G., Maxwell, L., Williams, A., ... Abrahams, N. (2017). Who perpetrates violence against children? A systematic analysis of age-specific and sex-specific data. BMJ Paediatrics Open, 2, e000180. https://doi.org/10.1136/bmjpo-2017-000180.

Douglas, E. M. (2006). Familial violence socialization in childhood and later life approval of corporal punishment: A cross-cultural perspective. The American Journal of Orthopsychiatry, 76(1), 23-30. https://doi.org/10.1037/0002-9432.76.1.23.

Dubowitz, H. (2007). Understanding and addressing the "neglect of neglect:" digging into the molehill. Child Abuse \& Neglect, 31(6), 603-606. https://doi.org/10. 1016/j.chiabu.2007.04.002.

Dubowitz, H. (2013). Neglect in children. Pediatric Annals, 42(4), 73-77. https://doi.org/10.3928/00904481-20130326-11.

Dubowitz, H., \& Bennett, S. (2007). Physical abuse and neglect of children. Lancet, 369(9576), 1891-1899. https://doi.org/10.1016/S0140-6736(07)60856-3.

Education Planning and Policy Analysis Department Ministry of Education Science Technology and Sports (2014). Statistical abstract 2014: Findings from the annual school census 2014. Retrieved from www.education.go.ug/files/downloads/Abstract 2014(1).pdf.

Ellison, C. G., \& Bradshaw, M. (2009). Religious beliefs, sociopolitical ideology, and attitudes toward corporal punishment. Journal of Family Issues, 30(3), 320-340. https://doi.org/10.1177/0192513X08326331.

Feinstein, S., \& Mwahombela, L. (2010). Corporal punishment in Tanzania's schools. International Review of Education, 56(4), 399-410. https://doi.org/10.1007/ s11159-010-9169-5.

Finkelhor, D., Ormrod, R. K., \& Turner, H. A. (2007). Poly-victimization: A neglected component in child victimization. Child Abuse \& Neglect, 31(1), 7-26. https://doi. org/10.1016/j.chiabu.2006.06.008.

Finkelhor, D., Ormrod, R., Turner, H., \& Holt, M. (2009). Pathways to poly-victimization. Child Maltreatment, 14(4), 316-329. https://doi.org/10.1177/ 1077559509347012.

Finkelhor, D., Shattuck, A., Turner, H. A., Ormrod, R., \& Hamby, S. L. (2011). Polyvictimization in developmental context. Journal of Child \& Adolescent Trauma, 4(4), 291-300. https://doi.org/10.1080/19361521.2011.610432.

Gershoff, E. T. (2017). School corporal punishment in global perspective: Prevalence, outcomes, and efforts at intervention. Psychology, Health \& Medicine, 22, 224-239. https://doi.org/10.1080/13548506.2016.1271955.

Goodman, R., Meltzer, H., \& Bailey, V. (1998). The strengths and difficulties questionnaire: A pilot study on the validity of the self-report version. European Child \& Adolescent Psychiatry, 7(3), 125-130. https://doi.org/10.1080/0954026021000046137.

Graham, S., \& Bellmore, A. D. (2007). Peer victimization and mental health during early adolescence. Theory Into Practice, 46(2), 138-146. https://doi.org/10.1080/ 00405840701233081

Grogan-Kaylor, A., Ma, J., \& Graham-Bermann, S. A. (2018). The case against physical punishment. Current Opinion in Psychology, 19, 22-27. https://doi.org/10.1016/ j.copsyc.2017.03.022.

Hart, S. N., Durrant, J., Newell, P., \& Power, F. C. (Eds.). (2005). Eliminating corporal punishment: The way forward to constructive child discipline. Paris: UNESCO.

Haslam, D., Gitonga, J., Okwach, J., Sanders, M., Johnson, C., \& Brown, J. (2011). Positive parenting for parents living in informal settlements in Kenya: Is Triple P relevant? Retrieved fromhttp://helpingfamilieschange.org/wp-content/uploads/2014/03/C3-Haslam-Gitonga-Okwach-Brown-Johnson.pdf.

Hecker, T., Boettcher, V. S., Landolt, M. A., \& Hermenau, K. (2019). Child neglect and its relation to emotional and behavioral problems: A cross-sectional study of primary school-aged children in Tanzania. Development and Psychopathology, 31(1), 325-339. https://doi.org/10.1017/S0954579417001882. 
Hecker, T., Goessmann, K., Nkuba, M., \& Hermenau, K. (2018). Teachers' stress intensifies violent disciplining in Tanzanian secondary schools. Child Abuse \& Neglect, 76, 173-183. https://doi.org/10.1016/j.chiabu.2017.10.019.

Hecker, T., Hermenau, K., Isele, D., \& Elbert, T. (2014). Corporal punishment and children's externalizing problems: A cross-sectional study of Tanzanian primary school aged children. Child Abuse \& Neglect, 38(5), 884-892. https://doi.org/10.1016/j.chiabu.2013.11.007.

Hecker, T., Hermenau, K., Salmen, C., Teicher, M., \& Elbert, T. (2016). Harsh discipline relates to internalizing problems and cognitive functioning: Findings from a cross-sectional study with school children in Tanzania. BMC Psychiatry, 16, 118. https://doi.org/10.1186/s12888-016-0828-3.

Hildyard, K. L., \& Wolfe, D. A. (2002). Child neglect: Developmental issues and outcomes. Child Abuse \& Neglect, 26(6-7), 679-695. https://doi.org/10.1016/s01452134(02)00341-1.

Hillis, S. D., Mercy, J. A., \& Saul, J. R. (2017). The enduring impact of violence against children. Psychology, Health \& Medicine, 22(4), 393-405. https://doi.org/10. 1080/13548506.2016.1153679.

Hoosen, N., Davids, E. L., de Vries, P. J., \& Shung-King, M. (2018). The Strengths and Difficulties Questionnaire (SDQ) in Africa: A scoping review of its application and validation. Child and Adolescent Psychiatry and Mental Health, 12, 6. https://doi.org/10.1186/s13034-017-0212-1.

Juvonen, J., \& Graham, S. (2014). Bullying in schools : The power of bullies and the plight of victims. Annual Review of Psychology, 65(1), 159-185. https://doi.org/10. 1146/annurev-psych-010213-115030.

Kamndaya, M., Pisa, P. T., Chersich, M. F., Decker, M. R., Olumide, A., Acharya, R., ... Delany-Moretlwe, S. (2017). Intersections between polyvictimisation and mental health among adolescents in five urban disadvantaged settings: The role of gender. BMC Public Health, 17(Suppl 3), 525. https://doi.org/10.1186/s12889-0174348-y.

Know Violence in Childhood (2017). Ending violence in childhood. Global Report 2017New Delhi, India Author.

Lansford, J. E., Cappa, C., Putnick, D. L., Bornstein, M. H., Deater-Deckard, K., \& Bradley, R. H. (2017). Change over time in parents' beliefs about and reported use of corporal punishment in eight countries with and without legal bans. Child Abuse \& Neglect, 71, 44-55. https://doi.org/10.1016/j.chiabu.2016.10.016.

Lansford, J. E., \& Dodge, K. A. (2008). Cultural norms for adult corporal punishment of children and societal rates of endorsement and use of violence. Parenting, Science and Practice, 8(3), 257-270. https://doi.org/10.1080/15295190802204843.

Lansford, J. E., Godwin, J., Tirado, L. M. U., Zelli, A., Al-Hassan, S. M., Bacchini, D., ... Alampay, L. P. (2015). Individual, family, and culture level contributions to child physical abuse and neglect: A longitudinal study in nine countries. Development and Psychopathology, 27(4 Pt 2), 1417-1428. https://doi.org/10.1017/ S095457941500084X.

Le, M. T. H., Holton, S., Romero, L., \& Fisher, J. (2018). Polyvictimization among children and adolescents in low-and lower-middle-income countries: A systematic review and meta-analysis. Trauma, Violence \& Abuse, 19(3), 323-342. https://doi.org/10.1177/1524838016659489.

Leoschut, L., \& Kafaar, Z. (2017). The frequency and predictors of poly-victimisation of South African children and the role of schools in its prevention. Psychology, Health \& Medicine, 22, 81-93. https://doi.org/10.1080/13548506.2016.1273533.

Lereya, S. T., Copeland, W. E., Costello, E. J., \& Wolke, D. (2015). Adult mental health consequences of peer bullying and maltreatment in childhood: Two cohorts in two countries. The Lancet Psychiatry, 2(6), 524-531. https://doi.org/10.1016/S2215-0366(15)00165-0.

Lereya, S. T., Samara, M., \& Wolke, D. (2013). Parenting behavior and the risk of becoming a victim and a bully/victim: A meta-analysis study. Child Abuse \& Neglect, 37(12), 1091-1108. https://doi.org/10.1016/j.chiabu.2013.03.001.

Maguire, S., \& Naughton, A. (2016). Neglect: Widespread, damaging and difficult to identify. Paediatrics and Child Health, 26(11), 485-487. https://doi.org/10.1016/j. paed.2016.06.010

Markowitz, F. E. (2011). Mental illness, crime, and violence: Risk, context, and social control. Aggression and Violent Behavior, 16(1), 36-44. https://doi.org/10.1016/j. avb.2010.10.003.

Mcsherry, D. (2007). Understanding and addressing the "neglect of neglect" : Why are we making a mole-hill out of a mountain? Child Abuse \& Neglect, 31, 607-614. https://doi.org/10.1016/j.chiabu.2006.08.011.

Mikolajczak, M., Elena, M., Avalosse, H., \& Roskam, I. (2018). Consequences of parental burnout : Its specific effect on child neglect and violence. Child Abuse \& Neglect, 80, 134-145. https://doi.org/10.1016/j.chiabu.2018.03.025.

Mohr, A. (2006). Family variables associated with peer victimization: Does family violence enhance the probability of being victimized by peers? Swiss Journal of Psychology, 65(2), 107-116. https://doi.org/10.1024/1421-0185.65.2.107.

Mulder, T. M., Kuiper, K. C., van der Put, C. E., Stams, G. J. M., \& Assink, M. (2018). Risk factors for child neglect: A meta-analytic review. Child Abuse \& Neglect, 77, 198-210. https://doi.org/10.1016/j.chiabu.2018.01.006.

Naker, D. (2005). Violence against children: The voices of Ugandan children and adults. Retrieved fromwww.raisingvoices.org.

Naker, D., \& Sekitoleko, D. (2009). Positive discipline: Alternatives to corporal punishment-creating a good school without corporal punishment. Retrieved fromwww. raisingvoices.org.

Nkuba, M., Hermenau, K., Goessmann, K., \& Hecker, T. (2018). Mental health problems and their association to violence and maltreatment in a nationally representative sample of Tanzanian secondary school students. Social Psychiatry and Psychiatric Epidemiology, 53(7), 699-707. https://doi.org/10.1007/s00127-0181511-4.

Nkuba, M., Hermenau, K., Goessmann, K., \& Hecker, T. (2018). Reducing violence by teachers using the preventive intervention Interaction Competencies with Children for Teachers (ICC-T): A cluster randomized controlled trial at secondary schools in Tanzania. PloS One, 13(8), e0201362. https://doi.org/10.1371/ journal pone.0201362.

Nkuba, M., Hermenau, K., \& Hecker, T. (2018). Violence and maltreatment in Tanzanian families—Findings from a nationally representative sample of secondary school students and their parents. Child Abuse \& Neglect, 77, 110-120. https://doi.org/10.1016/j.chiabu.2018.01.002.

Nkuba, M., Hermenau, K., \& Hecker, T. (2019). The association of maltreatment and socially deviant behavior-Findings from a national study with adolescent students and their parents. Mental Health \& Prevention, 13, 159-168. https://doi.org/10.1016/j.mhp.2019.01.003.

Norman, R. E., Byambaa, M., De, R., Butchart, A., Scott, J., \& Vos, T. (2012). The long-term health consequences of child physical abuse, emotional abuse, and neglect: A systematic review and meta-analysis. PLoS Medicine, 9(11), e1001349. https://doi.org/10.1371/journal.pmed.1001349.

Pinheiro, P. S. (2006). World report on violence against children. United Nations Secretary-General's study on violence against childrenRetrieved from https://www.unicef.org/violencestudy/I. World Report on Violence against Children.pdf.

Preacher, K. J., \& Hayes, A. F. (2004). SPSS and SAS procedures for estimating indirect effects in simple mediation models. Behavior Research Methods Instruments \& Computers, 36(4), 717-731. https://doi.org/10.3758/BF03206553.

Sanders, M. R. (2012). Development, evaluation, and multinational dissemination of the Triple P-positive parenting program. Annual Review of Clinical Psychology, 8(1), 345-379. https://doi.org/10.1146/annurev-clinpsy-032511-143104.

Ssenyonga, J., Hermenau, K., Nkuba, M., \& Hecker, T. (2019). Stress and positive attitudes towards violent discipline are associated with Teachers use of violence in Uganda. Child Abuse and Neglect, 93, 15-26. https://doi.org/10.1016/j.chiabu.2019.04.012.

Stith, S. M., Liu, T., Davies, L. C., Boykin, E. L., Alder, M. C., Harris, J. M., ... Dees, J. E. M. E. G. (2009). Aggression and violent behavior risk factors in child maltreatment : A meta-analytic review of the literature. Aggression and Violent Behavior, 14(1), 13-29. https://doi.org/10.1016/j.avb.2006.03.006.

Stoltenborgh, M., Bakermans-Kranenburg, M. J., Alink, L. R. A., \& van Ijzendoorn, M. H. (2015). The prevalence of child maltreatment across the globe: Review of a series of meta-analyses. Child Abuse Review, 24, 37-50. https://doi.org/10.1002/car.

Stoltenborgh, M., Bakermans-Kranenburg, M. J., \& Van Ijzendoorn, M. H. (2013). The neglect of child neglect: A meta-analytic review of the prevalence of neglect. Social Psychiatry and Psychiatric Epidemiology, 48(3), 345-355. https://doi.org/10.1007/s00127-012-0549-y.

Straus, M. A. (2000). Corporal punishment and primary prevention of physical abuse. Child Abuse \& Neglect, 24(9), 1109-1114. https://doi.org/10.1016/S01452134(00)00180-0.

Straus, M. A. (2007). Conflict tactics scales. In N. A. Jackson (Ed.). Encyclopedia of domestic violence (pp. 190-197). New York: Taylor \& Francis. https://doi.org/10. 1016/S0140-6736(05)17884-2.

Straus, M. A. (2010). Prevalence, societal causes, and trends in corporal punishment by parents in world perspective. Law and Contemporary Problems, 73(1), 1-30. 
https://doi.org/10.2307/25766385.

Stuart, H. (2003). Violence and mental illness: An overview. World Psychiatry, 2(2), 121-124.

Taylor, C. A., Hamvas, L., Rice, J., Newman, D. L., \& DeJong, W. (2011). Perceived social norms, expectations, and attitudes toward corporal punishment among an urban community sample of parents. Journal of Urban Health, 88(2), 254-269. https://doi.org/10.1007/s11524-011-9548-7.

Teicher, M. H., \& Parigger, A. (2015). The "Maltreatment and Abuse Chronology of Exposure" (MACE) scale for the retrospective assessment of abuse and neglect during development. PloS One, 10(2), e0117423. https://doi.org/10.1371/journal.pone.0117423.

Thumann, B. F., Nur, U., Naker, D., \& Devries, K. M. (2016). Primary school students' mental health in Uganda and its association with school violence, connectedness, and school characteristics: A cross-sectional study. BMC Public Health, 16, 662. https://doi.org/10.1186/s12889-016-3351-z.

Turner, H. A., Finkelhor, D., \& Ormrod, R. (2010). Poly-victimization in a national sample of children and youth. American Journal of Preventive Medicine, 38(3), 323-330. https://doi.org/10.1016/j.amepre.2009.11.012.

UNICEF (2012). Child maltreatment: Prevalence, incidence and consequences in the East Asia and Pacific Region: A systematic review of research. Bangkok: UNICEF East Asia and Pacific Region Office.

UNICEF (2014). Hidden in Plain Sight: A statistical analysis of violence against children. New York: UNICEF.

UNICEF (2016). The state of the world's children 2016: A fair chance for every child. Retrieved fromhttps://www.unicef.org/publications/files/UNICEF_SOWC_2016.pdf.

UNICEF (2017). A familiar face: Violence in the lives of children and adolescent. Retrieved fromhttps://www.unicef.org/publications/files/Violence_in_the_lives_of children_and_adolescents.pdf.

United Nations (2016). Toward a world free from violence: Global survey on violence against children. Retrieved fromhttps://doi.org/10.18356/2442f8ad-en.

Wandera, S. O., Clarke, K., Knight, L., Allen, E., Walakira, E., Namy, S., ... Devries, K. (2017). Violence against children perpetrated by peers: A cross-sectional schoolbased survey in Uganda. Child Abuse \& Neglect, 68, 65-73. https://doi.org/10.1016/j.chiabu.2017.04.006.

Xia, Y., Li, S. D., \& Liu, T. H. (2018). The interrelationship between family violence, adolescent violence, and adolescent violent victimization: An application and extension of the cultural spillover theory in China. International Journal of Environmental Research and Public Health, 15(2), 371. https://doi.org/10.3390/ ijerph15020371. 